openUP

\title{
THE EFFECT OF YOUTH ALCOHOL INITIATION ON HIGH SCHOOL COMPLETION
}

\author{
Steven F. Koch and Kerry Anne
}

\begin{abstract}
ABBREVIATIONS
GED: Graduate Equivalency Degree NLSY: National Longitudinal Study of Youth
\end{abstract}

Abstract

The social environment inherent in schools impacts both alcohol consumption onset and high school completion. The results reported here, based on data from the 1979-96 NLSY panels, show that the social coincidences between alcohol consumption and education are important determinants of both education completion and alcohol onset. Ignoring the social nature of these simultaneous decisions underestimates the impact of alcohol onset on education. After correcting for the presence of an endogenous positive relationship between schooling and alcohol consumption, we find that alcohol initiation before age 14 significantly reduces the probability of timeously completing high school by between 7\% and $22 \%$.

\section{INTRODUCTION}

Alcohol consumption by youths is viewed as a critical problem in the United States, and research concerning the effects of youth alcohol consumption has borne out this view. Grant and Dawson (1997), Moore and Cook (1995), and Wilson et al. (2002) find that youths who drink at an earlier age are more susceptible to future problem drinking. Figlio (1995) finds that youthful consumers of alcohol are more likely to be involved in traffic accidents. Furthermore, Benham and Benham (1982), Cook and Moore (1993), Mullahy and Sindelar (1994), and Yamada et al. (1996) find that these same youths are less likely to succeed in school. More generally, heavy and problem drinking reduces adult earnings, as evidenced in Harwood et al. (1984), Mullahy and Sindelar (1993), Rice et al. (1990), and Rice (1993). The preceding results have influenced federal legislative efforts to raise the minimum legal drinking age to 21 years, reductions in the availability of alcohol on college campuses, increased conspicuousness of youth driver's licenses, and increased civil and criminal penalties for adults who furnish alcohol to minors.

Although a large body of research, prime examples of which have already been cited, shows a strong negative relationship between alcohol consumption and measures of socioeconomic status, other researchers have called these results into question. For example, Dee and Evans (1999) find minimal effects of youth drinking on education. In addition, although Burgess and Propper (1998) find detrimental future effects due to behavioral problems in early life, early alcohol consumption would not be defined as a behavioral problem, due to its negligible effects on later life outcomes. Also, Koch and 
Ribar (2001) show that increasing the age of alcohol consumption onset does not appreciably increase the years of completed schooling.

It is possible that Burgess and Propper's (1998) and Koch and Ribar's (2001) results are due to the fact that they examine outcomes years afterward. Burgess and Propper examine productivity and household formation 10 years after the problem is uncovered, and Koch and Ribar examine education completion at age 25, which is 8 years beyond the sample average alcohol consumption onset. Therefore, many of the people in these analyses may have had trouble with alcohol during their high school years but were able to return to a more productive lifestyle later. In that case, these two aforementioned research projects may not have uncovered the true effects of early alcohol use. Although these papers, as well as Dee and Evans (1999), take care to instrument for the simultaneity between schooling decisions and alcohol consumption decisions, little consideration is given to the social complementarities of alcohol consumption and schooling. For example, Koch and Ribar (2001) use sibling data to control for withinfamily similarities in the propensity to consume alcohol and obtain further education; Burgess and Propper (1998) include few controls for endogeneity' Dee and Evans (1999) use state-level cohort data, where there are unlikely to be any peer effects concerning drinking and schooling decisions.

In this article, we examine more carefully the relationship between youthful drinking and high school success using data from the 1979-96 panels of the National Longitudinal Survey of Youth (NLSY). High school-aged individuals are chosen in an effort to see whether youthful alcohol consumption initiation, rather than contemporaneous consumption, affects education attainment in the short run. Initiation is important because short-run adverse education consequences may result in large cumulative effects on human capital and later socioeconomic status. The fact that high school and the onset of drinking occur proximately for much of the sample makes the estimation of a direct effect of alcohol consumption onset on school progress plausible.

We find that alcohol consumption onset has a statistically significant negative influence on high school completion. In addition, we find that failure to control endogeneity, which could work through the social intricacies of high school because students are likely to form peer groups and those peer groups are likely to significantly influence student drinking and schooling behavior, leads to results that are largely understated. For instance, we find that after controlling for potential social factors, a young student, who had initiated regular alcohol consumption by the age of 14 , would be nearly one-quarter less likely to receive a high school diploma by the age of 20; young alcohol consumers are nearly one-tenth less likely to complete high school, either through a diploma or a General Equivalency Degree (GED) by the age of 20. Most tellingly, youths who had begun to regularly consume alcohol by the age of 14 and had dropped out of school were nearly one-half as likely to complete their high school education after the age of 20 than those who did not regularly consume alcohol by the age of 14 . These estimated negative effects are much larger than were estimated when ignoring the endogeneity between alcohol consumption and schooling decisions. 
The rest of this article is organized as follows. In section II, we provide economic explanations for why early drinking might be negatively associated with progress in education and further review some of the empirical literature on the subject. We continue in section III by describing the statistical issues associated with modeling these relationships and laying out our econometric approach. In section IV, we describe the data sources and variables used in the analysis, as well as highlight differences between and across data subsamples. Estimation results and specification comparisons are reported and discussed in section V. Section VI contains conclusions and recommendations for further research.

\section{BACKGROUND}

The effect of alcohol consumption on schooling is examined in the context of a simple model of human capital investment, similar to Becker (1965) or Grossman (1972). Children are endowed at birth with a basic level of human capital, which includes natural affinities to certain activities (physical and intellectual), inherent healthfulness, and other genetic information. Human capital evolves through childhood due primarily to parental actions (or the work of others who might be raising or surrounding the child). As children age, they start making decisions for themselves. In this article, we consider how and for how long adolescent decisions regarding alcohol use will affect the child's education completion.

In addition to the assumptions concerning childhood endowments, we assume that progress in school requires time in the form of attendance and studying, and the consumption of alcohol is assumed to require money and time expenditures. Assuming youths have preferences regarding schooling, drinking, and their consumption of other goods, a direct negative effect of drinking on schooling is plausible if it diverts individual resources away from schooling. Drinking might have other negative spillover effects on schooling progress if investments in education are less productive, due to alcohol consumption. For example, Weschler et al. (2000) report that alcohol binge drinking by college students makes them less likely to attend class or stay current with their studies. If there are negative psychological effects related to consumption, alcohol consumption might lower the individual's desire or ability to perform. For example, recent biological research by Deas and colleagues (2000) suggests that brain function may be adversely affected by youthful alcohol abuse.

Although contemporaneous trade-offs between studying and drinking imply a direct adverse effect of drinking on schooling progress, the model is also consistent with other explanations for a negative association. School advancement and alcohol consumption, as suggested at the outset, also depend on family background characteristics, like parental supervision or parental attitudes to alcohol consumption. Attitudes regarding schooling and drinking are also likely to be shaped by peer influences and other childhood experiences. Ignoring these relevant characteristics might lead to the estimation of a spurious negative correlation between adolescent drinking behavior and schooling progress, or might bias the estimated correlation negatively or positively. 
It is possible however, that dropping out of school can more easily support alcohol consumption. ${ }^{1}$ In this case, school leaving may have drinking consequences rather than the other way around. Accordingly, the examination of educational progress, or any other potential socioeconomic consequence, and alcohol consumption must consider issues of omitted variables and endogeneity bias. In our analysis, however, we account for alcohol consumption onset at the age of 14, the age at which most people enter high school. Using a measure of alcohol consumption, which predates the schooling continuation decision(s), eliminates contemporaneous endogeneity bias. ${ }^{2}$ However, as our model suggests, many childhood background characteristics, which are not completely observable, should be included in the estimation. If we are not able to include them, it is necessary to allow for the probable correlation between the unobservables in each equation. The complete model, which will be discussed in section III, will allow for correlations between the unobservable determinants of drinking onset and education completion.

The link between alcohol consumption and education has been examined as early as Benham and Benham (1982). Employing a sample of St. Louis youths from the 1910s and 1920s, who were surveyed again 30 years later, they found that drinking problems reduced schooling by about 1.5 years. Cook and Moore (1993), using the NLSY, as we do, estimated structural and reduced form equations for education completion (including highest year completed and college graduation) and youthful alcohol consumption (measured by drinks per week, frequency of drinking, and frequency of being drunk). To allay concerns over endogeneity bias, they used state beer taxes and minimum drinking age laws as instruments for alcohol consumption. Their instrumental variables procedures generated large but relatively imprecise estimates of the effect of drinking on schooling. ${ }^{3}$ As a check, they provided reduced form estimates showing that individuals from states with higher minimum drinking age laws and higher beer taxes were more likely to complete high school.

We cannot be certain, however, that Cook and Moore's (1993) estimated effect of alcohol policy variables on schooling is, itself, not spurious. Dee and Evans (1999) show that college entrance is less likely in states with higher cigarette excise taxes, with lower taxes on gasoline, without gun purchase waiting periods, with a death penalty, and with a 65 mph speed limit on the freeway. Their results imply that education policy and outcomes are linked to other government policies within a state, and for that reason, the use of within-state alcohol control policies may not be acting on education outcomes through its effect on drinking, but rather through its relation to within state policy goals. Dee and Evans continue by applying a two sample instrumental variables estimator to show that education attainment is not affected by youthful drinking.

Mullahy and Sindelar (1994) used cross-sectional data from the New Haven site of the National Institute of Mental Health Epidemiological Catchment Area survey and found that onset of alcoholism symptoms by age 22 reduced schooling by $5 \%$. Unfortunately, if youths in New Haven are not representative of youths in the rest of the country, their results cannot be generalized. ${ }^{4}$ More important, however, they are unable to control for 
potential endogeneity between schooling and alcoholism onset, and therefore we cannot be certain whether their results represent an upper bound or a lower bound.

Yamada et al. (1996), who also used data from the NLSY to estimate the effects of alcohol consumption on education, found that a $10 \%$ increase in the frequency of drinking reduced the graduation probability by $6.5 \%$. Their model used high school completion for the class of 1981 as the dependent variable, which we do not do. Rather, our analysis focuses on other schooling behaviors, of which direct graduation is just one. Therefore, we are able to examine a much larger group of high school students. In addition, although they do model substance demand, which they assume affects graduation, they do not allow for the possibility that the errors across the two equations could be correlated (endogeneity). For these reasons, it is uncertain if their results can be generalized.

Recognizing that scant attention has been paid to potential endogeneity issues surrounding schooling and alcohol consumption by youths, Koch and Ribar (2001) examine the effect of different endogeneity assumptions, and their respective biases in an effort to provide bounds on the estimates. Their analysis used same-sex sibling alcohol consumption onset as instruments for the individual's drinking behavior. Their analysis found that a one-year increase in the age of alcohol consumption onset did not measurably increase the number of years of completed schooling. The small magnitude of their results may be due to the fact that their instruments were not strong predictors of drinking behavior. The small magnitude could also have been obtained because they measured completed education at the age of 25, nearly 10 years later than the average age for alcohol onset, and if youthful alcohol consumption only causes short-term problems, their estimates may not encompass those short-term problems. ${ }^{5}$ Endogeneity corrections showed that any negative effects of drinking were understated. However, even including the endogeneity corrections, the upper bound estimate was an increase in schooling of less than one-half year for every one-year increase in the age of alcohol onset.

Most recently, Wolaver (2002) studied the intensive margin relating to youthful alcohol consumption and education. Using cross-sectional data from the 1993 Harvard College Alcohol Study, she finds that if college students are often intoxicated or are frequent binge drinkers, they attend classes less regularly, their average grade points are lower, and they have a higher probability of majoring in business (compared to engineering). Her results show that treating heavy alcohol use as exogenous to the schooling decision is inappropriate, although light alcohol consumption may be exogenous. Moreover, not treating the endogeneity understates the adverse effect on college education caused by heavy alcohol consumption.

We examine the effect of early alcohol consumption on educational attainment, as measured by high school completion (via diploma and/or GED). Importantly, the design of our analysis, where alcohol initiation occurs before education decisions are made, eliminates the potential problem of simultaneity; therefore, it is not reasonable to argue that education decisions affect early alcohol consumption decisions. However, it is expected, as has been shown in many of the preceding publications, that there are 
underlying unobservable variables impacting schooling and alcohol consumption decisions, especially peer interactions and the structure of social relationships during the high school years. These unobserved influences, if ignored in the analysis, could bias the estimates. Our expectation is that these unobservable variables understate the negative effects of alcohol consumption onset on education, as many of the preceding studies suggest.

\section{MODEL}

\section{Bivariate Probit}

In this article, we examine an empirical model, which measures the determinants of alcohol consumption onset and high school completion. ${ }^{6}$ We define $E_{i}^{*}$ as individual $i$ 's propensity to complete high school conditional on alcohol consumption onset, $A_{i}$, as well as other demographic and sociological factors. We assume in particular that $E_{i}^{*}$ is a function of these factors, such that:

$$
E_{i}^{*}=f\left(A_{i} \beta_{A}+X_{i} \theta\right)+\varepsilon_{i},
$$

where $X_{i}$ is a $1 \times k$ matrix of observed determinants, $\theta$ is a $k \times 1$ vector of associated coefficients, $A_{i}$ is alcohol consumption onset preceding high school, $\beta_{A}$ is the corresponding coefficient, and $\mathrm{k}_{i}$ is unobserved variation. The high school completion decision for individual $i$ is

$$
E_{i}=\left\{\begin{array}{cc}
1 \text { (completed high } \\
\text { school) } \\
0 \begin{array}{c}
\text { (does not } \\
\text { complete) },
\end{array} & \text { if } E_{i}^{*}>0 \\
\text { otherwise }
\end{array}\right.
$$

The different definitions of completion are discussed in section IV.

In the same fashion, we define $A_{i}^{*}$ as the propensity to begin drinking by the time high school begins for individual $i$. We assume that $A_{i}^{*}$ is a function of economic and sociological factors, such that

$$
A_{i}^{*}=g\left(Z_{i} \Gamma\right)+v_{i},
$$

where $Z_{i}$ denotes a $1 \times m$ matrix of observed explanatory variables, with an $m \times 1$ vector of corresponding coefficients, $\Gamma$, and $v_{i}$ represents unobserved variation. Alcohol consumption initiation preceding high school is a dichotomous variable given by ${ }^{7}$ 


$$
A_{i}=\left\{\begin{array}{cc}
1 \text { (onset by high } & \\
\text { school), } & \text { if } A_{i}^{*}>0 \\
0 \text { (onset later or } & \\
\text { not at all), } & \text { otherwise. }
\end{array}\right.
$$

The unobserved variations in equations (1) and (3) are assumed to be joint normally distributed:

$$
\left[\begin{array}{l}
\varepsilon_{i} \\
v_{i}
\end{array}\right] \sim N\left[\left(\begin{array}{l}
0 \\
0
\end{array}\right),\left(\begin{array}{cc}
\sigma_{\varepsilon}^{2} & \rho \sigma_{\varepsilon} \sigma_{v} \\
& \sigma_{v}^{2}
\end{array}\right)\right]
$$

Therefore, high school completion is specified as a probit with alcohol consumption initiation preceding high school as a dummy endogenous determinant.

Maximum likelihood estimation of equations (1), (3), and the distributional assumption (5) can be performed quite readily. However, to estimate the likelihood function, a few identification issues must be addressed. Unfortunately, the coefficient and error variance estimates can only be identified up to their proportions; therefore, we only know $\beta_{A} / \sigma_{\mathrm{s}}$, $\theta / \sigma \varepsilon$, and $\Gamma / \sigma_{v} .{ }^{8}$ In addition to only knowing proportions, the effect of alcohol consumption onset on high school completion cannot be determined without appropriate exclusion restrictions. ${ }^{9}$ Appropriately excluded variables from $X_{i}$ should be related to alcohol consumption onset but unrelated to high school completion. In our analysis, we use three such variables: the log beer tax rate that the individual faces at the age of 14 , the minimum legal drinking age faced by the individual at the age of 14, and whether the individual knows close relatives with an alcohol problem.

If equations (1) and (3) are specified such that there is no possibility for correlation between their associated errors, then endogeneity bias is not a concern, and the estimated correlation coefficient, $\rho$, will be zero. In that case, separate probit estimation of the two equations, is appropriate. Although we are primarily concerned with the estimate of $\beta_{A}$, we provide, as a point of comparison, the results of the probit estimates alongside the results of the bivariate probit estimates.

\section{DATA}

The data for this analysis come from the 1979-96 panels of the NLSY (Center for Human Resource Research, 1998). The NLSY is a national sample of 12,686 individuals, who were 14-21 years old in 1979 and have been reinterviewed annually since then. ${ }^{10}$ The survey contains detailed longitudinal behavioral information, including data on schooling progress and alcohol consumption at different ages; unfortunately, alcohol questions were not asked yearly. Personal, peer, family background, and local area data (which allows us to match the data with state-level information on taxes and legal drinking ages) are also available in the NLSY. 
We have created subsamples from the NLSY based on gender and schooling achievement. The gender subsamples are only used to portray the differences between men and women in their education success and their alcohol consumption onset. ${ }^{11}$ The education subsamples are the basis of the analysis within the article.

For determining the effect of youthful alcohol consumption on normal high school progress and completion, we primarily focused on dichotomous measures of high school completion versus noncompletion. However, these dichotomous measures were created from three basic schooling completion measures: (1) receipt of a high school diploma by the age of 20; (2) receipt of a high school diploma after the age of 20 or a GED; and (3) no receipt of a recognized high school degree within the sample period. ${ }^{12}$ Given the age of the NLSY respondents, the majority of high school completions in the later years of the NLSY survey were through the GED, although the total number of GED recipients is small (slightly less than $10 \%$ of the women, and slightly less than $11 \%$ of the men in the sample have earned a GED).

TABLE 1

Frequency of Early Alcohol Consumption Onset and High School Completion Measures for the Female and Male Subsamples

\begin{tabular}{lcccc}
\hline & $\begin{array}{c}\text { Has Not Received } \\
\text { a HS Degree }\end{array}$ & $\begin{array}{c}\text { HS Diploma after } \\
\text { Age 20 or a GED }\end{array}$ & $\begin{array}{c}\text { High School Diploma } \\
\text { by Age 20 }\end{array}$ & $\begin{array}{c}\text { Cumulative Alcohol } \\
\text { Onset }^{\mathbf{a}}\end{array}$ \\
\hline Females & 588 & 585 & 3148 & 4321 \\
Alcohol onset after 14 & 12.38 & 12.32 & 66.29 & 90.99 \\
\% of total sample & 82 & 86 & 260 & 428 \\
Alcohol onset by 14 & 1.73 & 1.81 & 5.47 & 9.01 \\
\% of total sample & 670 & 671 & 3408 & 4749 \\
Cumulative schooling & 14.11 & 14.13 & 71.76 & 100 \\
$\%$ of total sample & 593 & 569 & 2425 & 3587 \\
Males & 13.47 & 12.93 & 55.1 & 81.5 \\
Alcohol onset after 14 & 213 & 177 & 424 & 814 \\
$\%$ of total sample & 4.84 & 4.02 & 9.63 & 18.5 \\
Alcohol onset by 14 & 806 & 746 & 2849 & 4401 \\
$\%$ of total sample & 18.31 & 16.95 & 64.74 & 100 \\
Cumulative schooling & & & & \\
$\%$ of total sample & & &
\end{tabular}

\footnotetext{
${ }^{a}$ Aggregation over each schooling measure leads to total number of youths.

${ }^{\mathrm{b}}$ Aggregation over each alcohol measure leads to total number of youths who have completed a particular level of schooling.

Source: Authors' calculations from NLSY 1979-96.
}

Similar to Koch and Ribar (2001), the age of alcohol consumption onset is constructed from the data. In 1982 and 1983, individuals were asked about the age at which they began to drink regularly; a dichotomous measure of drinking by the age of 14 could be constructed from the 1982 and 1983 survey questions, because the entire sample was at least 16 years of age by the time of the 1982 panel. ${ }^{13}$ Because individuals were not interviewed until they were 14 years old, the typical age of eighth- and ninth-graders, and could have been as old as 22 years, a large component of the analysis is based on retrospective data. ${ }^{14}$ The age of 14 was chosen because it is the average age of a ninth- 
grader. Therefore, the investigation can focus on whether drinking, preceding high school, has any effect on the individual's normal successful completion of high school.

\section{Alcohol Consumption Onset by Age 14 and Schooling Completion Differences}

Table 1 illustrates the detrimental effect of early alcohol consumption onset on high school completion. Although the remainder of the analysis is based on a pooled sample of males and females, the schooling and alcohol onset frequencies are presented by gender in Table $1 .^{15}$ The table highlights the differences between drinking and schooling behavior between men and women. Although the majority of women, $71.8 \%$, and men, $64.7 \%$, receive their high school diploma by the age of 20 , alcohol consumption onset preceding high school is associated with a reduced probability of completion. For example, considering only the youths who do not initiate alcohol consumption by the age of $14,27.1 \%$ of these women do not receive a diploma by the age of 20 ; on the other hand, for the women who initiated alcohol consumption by the age of 14 , over $39.3 \%$ of them fail to complete their diplomas by the age of $20 .{ }^{16}$ For the men, the numbers are similarly sobering.

TABLE 2

Sample Statistics of Family Variables Used in the Analysis by Measure of School Completion

\begin{tabular}{|c|c|c|c|c|c|c|}
\hline \multirow[b]{2}{*}{ Variable } & \multicolumn{2}{|c|}{$\begin{array}{c}\text { No GED or Diploma } \\
\text { by Any Age } \\
N=1,476\end{array}$} & \multicolumn{2}{|c|}{$\begin{array}{c}\text { Diploma after Age } \\
20 \text { or a GED } \\
N=1,417\end{array}$} & \multicolumn{2}{|c|}{$\begin{array}{c}\text { Diploma Received } \\
\text { by Age } 20 \\
N=6,257\end{array}$} \\
\hline & Mean & SD & Mean & SD & Mean & SD \\
\hline Male $=1$ if male & 0.546 & 0.498 & 0.526 & 0.499 & 0.455 & 0.498 \\
\hline Nonwhite $=1$ if not white & 0.486 & 0.500 & 0.519 & 0.500 & 0.375 & 0.484 \\
\hline $\begin{array}{l}\% \text { FamInt }=\text { proportion to age } 14 \text { boi family } \\
\text { was together }\end{array}$ & 0.721 & 0.399 & 0.716 & 0.398 & 0.838 & 0.331 \\
\hline$\%$ FamIntMiss $=1$ if $\%$ FamInt not available & 0.014 & 0.018 & 0.014 & 0.118 & 0.009 & 0.094 \\
\hline Siblings $=$ number of siblings & 4.752 & 2.874 & 4.339 & 2.873 & 3.489 & 2.410 \\
\hline NotOldest $=1$ if not oldest child & 0.741 & 0.438 & 0.702 & 0.457 & 0.671 & 0.470 \\
\hline $\begin{array}{l}\text { OlderSibHS }=1 \text { if older sibling completed } \\
\text { high school }\end{array}$ & 0.380 & 0.486 & 0.440 & 0.497 & 0.570 & 0.495 \\
\hline MomEd $=$ mom years of education & 8.332 & 4.162 & 9.215 & 4.047 & 11.047 & 3.600 \\
\hline MomEdMiss $=1$ if mom education not available & 0.108 & 0.311 & 0.077 & 0.267 & 0.038 & 0.192 \\
\hline DadEd $=$ dad years of education & 6.909 & 5.046 & 7.927 & 5.154 & 10.458 & 5.024 \\
\hline DadEdMiss $=1$ if not available & 0.226 & 0.419 & 0.197 & 0.398 & 0.105 & 0.307 \\
\hline $\begin{array}{l}\text { Reading Available }=3 \text { if magazine library card } \\
\text { and newspapers; } 2 \text { if only } 2 \text { of } 3 ; 1 \text { if } 1 \text { of } 3 ; \\
0 \text { if none }\end{array}$ & 1.484 & 1.032 & 1.768 & 1.039 & 2.206 & 0.929 \\
\hline Raised Catholic $=1$ if Catholic & 0.301 & 0.459 & 0.330 & 0.470 & 0.335 & 0.472 \\
\hline $\begin{array}{l}\text { Religious }=1 \text { if attended church at least twice } \\
\text { per month }\end{array}$ & 0.344 & 0.475 & 0.368 & 0.483 & 0.500 & 0.500 \\
\hline Urban $=1$ if lived in city at age 14 & 0.793 & 0.406 & 0.819 & 0.385 & 0.780 & 0.414 \\
\hline$\%$ HSDip $=\%$ of local population with diploma & 48.231 & 12.067 & 49.379 & 11.440 & 51.319 & 11.110 \\
\hline
\end{tabular}

Source: Authors' calculation from NLSY 1979-96.

Over $47.8 \%$ of the men who consumed alcohol regularly by the age of 14 do not complete their diplomas by the age of 20 . On the other hand, only $32.1 \%$ of the men who have not initiated alcohol consumption by the age of 14 do not manage to complete their high school diplomas in a timely manner. ${ }^{17}$ The table also shows that women are more 
openUP

likely to complete a diploma by the age of 20 , whereas men are more likely to initiate alcohol consumption by the age of $14 .{ }^{18}$ Furthermore, the hypothesis that each of the female and male subsamples has the same likelihood of drinking by the age of 14 is rejected by a Kruskal-Wallis test. ${ }^{19}$

\section{Summary Statistics of Data Used in the Analysis}

Tables 2 and 3 contain summary statistics for the: family background characteristics of the female high school subsample, family background characteristics of the male subsample, and local area and other characteristics for the pooled sample. The tables also contain definitions of all of the variables used in the analysis and are further disaggregated by our schooling completion measure.

The data reported in Table 2 lend some credence to Becker's (1991) theory of the family: Children in larger families have less success in school, possibly because limited parental resources are spread more thinly over the children, the quality of those resources may also be lower, mothers and fathers average less completed education, older siblings were less likely to graduate from high school, and fewer reading materials were available to the children. The average family of a nongraduate was intact for a shorter period of time preceding the child's high school education than a diploma recipient. In addition, the diploma recipient, more often, was raised in an area with a higher high school completion rate.

TABLE 3

Sample Statistics of Personal and Location Variables Used in the Analysis by Measure of School Completion

\begin{tabular}{|c|c|c|c|c|c|c|}
\hline \multirow[b]{2}{*}{ Variable } & \multicolumn{2}{|c|}{$\begin{array}{c}\text { No GED or Diploma } \\
\text { by Any Age } \\
N=1,476\end{array}$} & \multicolumn{2}{|c|}{$\begin{array}{c}\text { Diploma after Age } \\
20 \text { or a GED } \\
N=1,417\end{array}$} & \multicolumn{2}{|c|}{$\begin{array}{c}\text { Diploma Received } \\
\text { by Age } 20 \\
N=6,257\end{array}$} \\
\hline & Mean & SD & Mean & SD & Mean & SD \\
\hline Onset at $14=11$ if initiate by 14 & 0.200 & 0.400 & 0.186 & 0.389 & 0.109 & 0.312 \\
\hline $\begin{array}{l}\text { One Relative }=1 \text { if knows one relative } \\
\text { with drinking problem }\end{array}$ & 0.512 & 0.500 & 0.534 & 0.499 & 0.494 & 0.500 \\
\hline $\begin{array}{l}\text { Two relatives }=1 \text { if knows two relatives } \\
\text { with drinking problem }\end{array}$ & 0.254 & 0.435 & 0.279 & 0.449 & 0.237 & 0.425 \\
\hline $\begin{array}{l}\text { MLDA14 }=\text { Minimum legal age for purchase } \\
\text { when aged } 14\end{array}$ & 19.038 & 1.367 & 18.946 & 1.317 & 18.995 & 1.339 \\
\hline LNtax $14=$ state beer tax when aged 14 & -0.766 & 1.036 & -0.787 & 1.003 & -0.816 & 0.955 \\
\hline AsvabVerb $=$ Score on ASVAB verbal section & 36.426 & 10.081 & 41.934 & 10.483 & 49.472 & 9.412 \\
\hline $\begin{array}{l}\text { RottInd = index summed over } 5 \text { questions } \\
\text { measuring own perception of control over own life }\end{array}$ & 10.583 & 2.258 & 10.805 & 2.406 & 11.533 & 2.382 \\
\hline
\end{tabular}

Source: Authors' calculation from NLSY 1979-96.

The descriptive data in Table 3 show that students who did not receive a high school diploma by the age of 20 felt less control over their lives (as measured by selfdetermination), had lower ASVAB verbal scores, ${ }^{20}$ and, most important, were less likely to initiate regular alcohol consumption by the age of 14 . On the other hand, students who completed their diploma by age 20 lived in states with lower beer taxes but were less aware of relatives with a drinking problem. However, there is no obvious pattern across education status for the state minimum legal drinking ages. The majority of the 
previously discussed differences in means across education subsamples carry through the analysis.

\section{RESULTS}

In this section we discuss the results from our specifications, which we examined over the entire sample of male and female students. ${ }^{21}$ The results are presented according to the identification exclusion restriction, if one was necessary. Therefore, in the first column, we present probit estimates for high school completion and youthful alcohol consumption onset; these probits were estimated based on the assumption that $\rho=0$, that is, there is no correlation between the unobserved error terms. In the second through last column, estimates of different bivariate probits are provided; the estimates in each column are based on different identification exclusion restrictions. Therefore, each of the last column headings defines which variable is used as the variable left out of the schooling equation for identification purposes. In addition, each of these last columns includes an estimate of the unobserved correlation between the high school completion equation and the alcohol consumption onset equation. Appropriate test statistics, standard errors, and significance notes are provided in each of the columns of each of the tables. Finally, in an effort to use space parsimoniously, only the main results are highlighted in the tables. 22

\section{Early Alcohol Consumption Initiation and High School Diploma Recipients}

Table 4 displays results from our estimates of high school completion, defined as receiving a high school diploma by the age of 20 (rather than not graduating, receiving a GED, or receiving a diploma later in life), and early alcohol consumption onset, defined as starting by the age of 14 . In other words, for the entire sample, ${ }^{23}$

$$
E_{i}=\left\{\begin{array}{cc}
1 \text { (receives a diploma } & \\
\text { by age } 20), & \text { if } E_{i}^{*}>0 \\
0(\text { does not receive a } & \\
\text { diploma by age } 20), & \text { otherwise. }
\end{array}\right.
$$

From the table, it is clear, as the discussion of the data in section IV suggests, that the probability of receiving a diploma declines significantly if the individual consumed alcohol on a regular basis before the age of 14. In addition, if we ignore unobservable but endogenous factors, the estimated impact is biased and understated; the mean of the calculated dummy endogenous marginal effects is $\approx 23 \%$, whereas the probit marginal effect estimate is only $10 \%$. Importantly, the choice of exclusion restriction does not greatly alter the estimated impact of early alcohol initiation on the probability of receiving a high school diploma. Although youthful alcohol consumption onset reduces the probability of a diploma, the results show that males are less negatively affected; the interaction between male and alcohol consumption onset yields a marginally positive and significant coefficient. 
openUP

TABLE 4

Estimates of Early Alcohol Consumption (by Age 14) on High School Diploma Receipt by Age 20

\begin{tabular}{|c|c|c|c|c|c|c|}
\hline \multirow[b]{2}{*}{ Sample $N=9150$} & \multirow[b]{2}{*}{ Probit Estimate } & \multicolumn{5}{|c|}{ Bivariate Probit Specification Exclusion Restriction for Onset by Age 14} \\
\hline & & MLDA14 & LNtax14 & One Rel & Two Rels & All Four \\
\hline $\begin{array}{l}\text { Effect on education by } \\
\text { Onset at age } 14\end{array}$ & $\begin{array}{r}-0.3654^{\mathrm{a}} \\
(0.0715)\end{array}$ & $\begin{array}{r}-1.4064^{\mathrm{a}} \\
(0.1934)\end{array}$ & $\begin{array}{r}-1.3597^{\mathrm{a}} \\
(0.2098)\end{array}$ & $\begin{array}{r}-1.4108^{\mathrm{a}} \\
(0.1666)\end{array}$ & $\begin{array}{r}-1.4017^{\mathrm{a}} \\
(0.1671)\end{array}$ & $\begin{array}{r}-1.4017^{\mathrm{a}} \\
(0.1623)\end{array}$ \\
\hline Marginal effect & $\begin{array}{r}-0.1301^{f} \\
(0.0268)\end{array}$ & $\begin{array}{r}-0.2273^{\mathrm{f}} \\
(0.1289)\end{array}$ & $\begin{array}{r}-0.2197^{f} \\
(0.1227)\end{array}$ & $\begin{array}{r}-0.2295^{\mathrm{f}} \\
(0.1310)\end{array}$ & $\begin{array}{r}-0.2299^{f} \\
(0.1314)\end{array}$ & $\begin{array}{l}-0.02292^{f} \\
(0.1309)\end{array}$ \\
\hline Male & $\begin{array}{r}0.4887^{\mathrm{b}} \\
(0.2086)\end{array}$ & $\begin{array}{r}0.7457^{\mathrm{a}} \\
(0.2093)\end{array}$ & $\begin{array}{r}0.7319^{\mathrm{a}} \\
(0.2109)\end{array}$ & $\begin{array}{r}0.7459^{\mathrm{a}} \\
(0.2071)\end{array}$ & $\begin{array}{r}0.7474^{\mathrm{f}} \\
(0.2074)\end{array}$ & $\begin{array}{l}0.7441^{\mathrm{a}} \\
(0.2071)\end{array}$ \\
\hline $\begin{array}{l}\text { Male } \times \text { Education } \\
\text { Effect of onset }\end{array}$ & $\begin{array}{c}0.0269 \\
(0.0897)\end{array}$ & $\begin{array}{r}0.1471^{f} \\
(0.0870)\end{array}$ & $\begin{array}{r}0.1397^{\mathrm{f}} \\
(0.0882)\end{array}$ & $\begin{array}{r}0.1464^{f} \\
(0.0858)\end{array}$ & $\begin{array}{r}0.1467^{\mathrm{f}} \\
(0.0858)\end{array}$ & $\begin{array}{r}0.1454^{\mathrm{f}} \\
(0.0857)\end{array}$ \\
\hline $\begin{array}{l}\text { Effect of MLDA14 } \\
\text { On Onset by } 14\end{array}$ & $\begin{array}{l}-0.018 \\
(0.0134)\end{array}$ & $\begin{array}{r}-0.0129 \\
(0.0124)\end{array}$ & & & & $\begin{array}{r}-0.0219^{c} \\
(0.0130)\end{array}$ \\
\hline $\begin{array}{l}\text { Effect of LNtax } 14 \\
\text { On Onset by } 14\end{array}$ & $\begin{array}{r}-0.0659^{\mathrm{a}} \\
(0.0211)\end{array}$ & & $\begin{array}{r}-0.0530^{\mathrm{a}} \\
(0.0198)\end{array}$ & & & $\begin{array}{r}-0.0624^{\mathrm{a}} \\
(0.0207)\end{array}$ \\
\hline $\begin{array}{l}\text { Effect of one relative } \\
\text { On Onset by } 14\end{array}$ & $\begin{array}{c}0.1636 \\
(0.0418)\end{array}$ & & & $\begin{array}{r}0.2617^{\mathrm{a}} \\
(0.0336)\end{array}$ & & $\begin{array}{r}0.1686^{\mathrm{a}} \\
(0.0405)\end{array}$ \\
\hline $\begin{array}{l}\text { Effect of Two relatives } \\
\text { On Onset by } 14\end{array}$ & $\begin{array}{c}0.1832 \\
(0.0456)\end{array}$ & & & & $\begin{array}{r}0.2943^{\mathrm{a}} \\
(0.0365)\end{array}$ & $\begin{array}{r}0.1876^{\mathrm{a}} \\
(0.0439)\end{array}$ \\
\hline Male & $\begin{array}{r}1.4417^{\mathrm{a}} \\
(0.2538)\end{array}$ & $\begin{array}{r}1.4831^{\mathrm{a}} \\
(0.2134)\end{array}$ & $\begin{array}{r}1.4921^{\mathrm{a}} \\
(0.2625)\end{array}$ & $\begin{array}{r}1.4854^{\mathrm{a}} \\
(0.2630)\end{array}$ & $\begin{array}{r}1.4848^{\mathrm{a}} \\
(0.2618)\end{array}$ & $\begin{array}{r}1.5090^{\mathrm{a}} \\
(0.2641)\end{array}$ \\
\hline$\rho$ & $0^{\mathrm{h}}$ & $0.5320^{\mathrm{a}}$ & $0.5093^{\mathrm{a}}$ & $0.5379^{\mathrm{a}}$ & $0.5394^{\mathrm{a}}$ & $0.5371^{\mathrm{a}}$ \\
\hline$\chi_{1}^{2}$ & & 21.634 & 17.226 & 30.61 & 30.373 & 32.411 \\
\hline Log likelihood & $-7,805.5^{\mathrm{e}}$ & $-7,839.49$ & $-7,836.42$ & $-7,809.32$ & $-7,808.8$ & $-7,795.23$ \\
\hline
\end{tabular}

Notes: SEs are in parentheses. Other variables used in regression and not reported in the table: Nonwhite, \%FamInt, \%FamIntMiss, Siblings, NotOldest, OlderSibHS, MomEd, MomEdMiss, DadEd, DadEdMiss, Reading Available, Raised Catholic, Religious, Urban, \%HSDip, Asvab Verb, and RottInd.

${ }^{a}$ Significant at $1 \%$.

${ }^{\mathrm{b}}$ Significant at $5 \%$.

${ }^{\mathrm{c}}$ Significant at $10 \%$.

${ }^{\mathrm{d}}$ Significant at $15 \%$.

'Sum of log-likelihoods from two separate probit estimates, one of school completion, the other from alcohol onset. ${ }^{\mathrm{f}}$ Marginal probability averaged over the entire sample.

${ }^{\mathrm{g}} \mathrm{SD}$ based on sample average marginal probability.

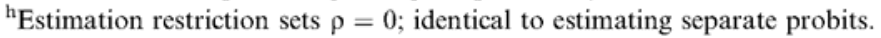

Source: NLSY 1979-96.

The most interesting feature of the results is the fact that the estimated effect of unobserved determinants is positive. For both males and females the $\chi_{1}^{2}$ statistic rejects the null hypothesis that the errors across the two equations are uncorrelated in all cases. As predicted by our previous discussion, the estimated unobserved correlation is positive, which means that unobserved factors, which increase (decrease) a youth's propensity to embark on an alcohol consumption path by the age of 14, also increase (decrease) the individual's propensity to receive a diploma by the age of 20 . Given the difficulty in controlling for peer and other social effects with the data available, the estimated $\rho>0$ is not surprising. Alcohol consumption is a social activity, and school is a highly social environment. The underpinning social nature of these two activities suggests an inherent complementarity between the two activities. ${ }^{24}$

Otherwise, most of the results are to be expected. We find that the decision to initiate alcohol consumption onset by the age of 14 is decreasing in the state policy variables, like the minimum legal drinking age in place at the time, as well as the beer tax rate at the 
time. ${ }^{25}$ In addition, we find that having knowledge of family members with a drinking problem is highly correlated with youthful alcohol consumption onset.

Although the rest of the results are not also reported, it is worth noting that the remaining variables reported in the data summary tables generally have the expected effect. Family intactness, school ability (ASVAB), religiosity, being nonwhite, and having an older sibling who has successfully completed high school, reduce the probability of youthful onset and raise the probability of schooling completion. Parental education and having access to various forms of reading material in the household raises the probability of own schooling success. In addition, Catholic youths with older siblings are more likely to have consumed alcohol on a regular basis by the age of 14 than otherwise similar youths. Finally, we find that children in larger families are less likely to successfully complete high school.

Note that if our choice of excluded variables are themselves endogenous, then the presented results are also biased. However, Dee and Evans (1999) suggest that the state determinants, not just drinking laws, are related to drinking; we also show that drinking laws are related to drinking behavior. However, we also show that knowledge of family alcohol problems leads to broadly similar estimated results. It is highly unlikely that these two different types of determinants are endogenous in the same way; therefore, we do not believe that the concern raised by Dee and Evans is a problem here. Furthermore, it is not clear that knowledge of family members with a drinking problem is endogenous to the decision to initiate alcohol consumption onset, given the fact that those family members are likely to have made their own decisions about alcohol consumption. ${ }^{26}$

\section{Association between Early Alcohol Consumption Onset and Diploma Recipients by Age 20 Compared to GED and Later-Life Diploma Recipients}

Due to differences between individuals who receive a diploma on time and those who receive either a GED or a later life diploma, we examine, more carefully, the differences between these two subgroups. The results from the analysis are reported in Table 5. This analysis is only performed on the sample of students who complete a recognizable high school degree. ${ }^{27}$ In other words, our education completion variable is:

$$
E_{i}=\left\{\begin{array}{cc}
1 \text { (receives a diploma } & \\
\text { by age } 20), & \text { if } E_{i}^{*}>0 \\
0 \text { (diploma after } 20 & \\
\text { or G.E.D. }), & \text { otherwise. }
\end{array}\right.
$$

The results presented in Table 5 are qualitatively similar to those presented in Table 4. For example, the unobserved correlation is positive and significant in all cases, with the exception of the state beer tax exclusion estimate, where it is positive and insignificant. The exclusion restrictions also produce similar estimates as reported in the previous subsection. 
openUP

TABLE 5

Estimates of Early Alcohol Consumption (by Age 14) on High School Completion (Diploma by Age 20 versus GED or Later-Life Diploma)

\begin{tabular}{|c|c|c|c|c|c|c|}
\hline \multirow[b]{2}{*}{ Sample $N=7,646$} & \multirow{2}{*}{$\begin{array}{l}\text { Probit } \\
\text { Estimate }\end{array}$} & \multicolumn{5}{|c|}{$\begin{array}{l}\text { Bivariate Probit Specification Exclusion } \\
\text { Restrictions for Onset by } 14\end{array}$} \\
\hline & & MLDA 14 & LNTax14 & One Rel. & Two Rels. & All Four \\
\hline $\begin{array}{l}\text { Effect on Education by } \\
\text { Onset at age } 14\end{array}$ & $\begin{array}{l}-0.3608^{\mathrm{a}} \\
(-0.0821)\end{array}$ & $\begin{array}{r}-0.9728^{\mathrm{b}} \\
(0.3902)\end{array}$ & $\begin{array}{r}-0.7397^{\mathrm{d}} \\
(0.4574)\end{array}$ & $\begin{array}{r}-1.1195^{\mathrm{a}} \\
(0.2399)\end{array}$ & $\begin{array}{r}-1.1352^{\mathrm{a}} \\
(0.2423)\end{array}$ & $\begin{array}{r}-1.1172^{\mathrm{a}} \\
(0.2287)\end{array}$ \\
\hline Marginal effect & $\begin{array}{r}-0.0953^{\mathrm{a}} \\
(0.0242)\end{array}$ & $\begin{array}{r}-0.1124^{f} \\
(0.0661)\end{array}$ & $\begin{array}{r}-0.0747^{f} \\
(0.0405)\end{array}$ & $\begin{array}{c}-0.01346^{\mathrm{f}} \\
(0.0837)\end{array}$ & $\begin{array}{r}-0.1369^{f} \\
(0.0856)\end{array}$ & $\begin{array}{c}-0.135^{\mathrm{f}} \\
(0.0840)\end{array}$ \\
\hline Male & $\begin{array}{r}0.3614^{\mathrm{c}} \\
(0.2126)\end{array}$ & $\begin{array}{r}0.4766^{\mathrm{b}} \\
(0.2221)\end{array}$ & $\begin{array}{r}0.4319^{\mathrm{c}} \\
(0.2278)\end{array}$ & $\begin{array}{r}0.4995^{\mathrm{b}} \\
(0.2126)\end{array}$ & $\begin{array}{c}0.505^{\mathrm{b}} \\
(0.2132)\end{array}$ & $\begin{array}{r}0.4978^{\mathrm{b}} \\
(0.2126)\end{array}$ \\
\hline Male $\times$ Education Effect of onset & $\begin{array}{c}0.0327 \\
(0.1045)\end{array}$ & $\begin{array}{c}0.0999 \\
(0.1108)\end{array}$ & $\begin{array}{c}0.0722 \\
(0.1146)\end{array}$ & $\begin{array}{c}0.1171 \\
(0.1039)\end{array}$ & $\begin{array}{c}0.1182 \\
(0.1035)\end{array}$ & $\begin{array}{c}0.1162 \\
(0.1034)\end{array}$ \\
\hline Effect of MLDA14 on Onset by 14 & $\begin{array}{c}-0.018 \\
(0.0149)\end{array}$ & $\begin{array}{c}-0.0125 \\
(0.0148)\end{array}$ & & & & $\begin{array}{r}-0.0224^{\mathrm{d}} \\
(0.0149)\end{array}$ \\
\hline Effect of LNtax14 on Onset by 14 & $\begin{array}{r}-0.0741^{\mathrm{a}} \\
(0.0234)\end{array}$ & & $\begin{array}{r}-0.0650^{\mathrm{a}} \\
(0.0230)\end{array}$ & & & $\begin{array}{r}-0.0695^{\mathrm{a}} \\
(0.0236)\end{array}$ \\
\hline Effect of one relative on Onset by 14 & $\begin{array}{l}0.164^{\mathrm{a}} \\
(0.0467)\end{array}$ & & & $\begin{array}{r}0.2803^{\mathrm{a}} \\
(0.0380)\end{array}$ & & $\begin{array}{r}0.1704^{\mathrm{a}} \\
(0.0461)\end{array}$ \\
\hline Effect of two relatives on Onset by 14 & $\begin{array}{r}0.2119^{\mathrm{a}} \\
(0.0506)\end{array}$ & & & & $\begin{array}{r}0.3256^{\mathrm{a}} \\
(0.0413)\end{array}$ & $\begin{array}{r}0.2179^{\mathrm{a}} \\
(0.0498)\end{array}$ \\
\hline Male & $\begin{array}{r}1.2757^{\mathrm{a}} \\
(0.2701)\end{array}$ & $\begin{array}{r}1.2439^{\mathrm{a}} \\
(0.2687)\end{array}$ & $\begin{array}{r}1.2565^{\mathrm{a}} \\
(0.2711)\end{array}$ & $\begin{array}{l}1.2195^{\mathrm{a}} \\
(0.2680)\end{array}$ & $\begin{array}{r}1.2286^{\mathrm{a}} \\
(0.2667)\end{array}$ & $\begin{array}{r}1.2326^{\mathrm{a}} \\
(0.2687)\end{array}$ \\
\hline$\rho$ & $0^{\mathrm{h}}$ & $0.3039^{\mathrm{d}}$ & 0.19 & $0.3790^{\mathrm{a}}$ & $0.3870^{\mathrm{a}}$ & $0.3799^{\mathrm{a}}$ \\
\hline$\chi_{1}^{2}$ & & 2.365 & 0.696 & 9.783 & 9.783 & 10.798 \\
\hline Log likelihood & $-5,838.76^{\mathrm{e}}$ & $-5,875.93$ & $-5,872.29$ & $-5,849.36$ & $-5,846.77$ & $-5,835.23$ \\
\hline
\end{tabular}

Notes: SEs are in parentheses. Other variables used in regression and not reported in the table: Nonwhite, \%FamInt, \%FamIntMiss, Siblings, NotOldest, OlderSibHS, MomEd, MomEdMiss, DadEd, DadEdMiss, Reading Available, Raised Catholic, Religious, Urban, \%HSDip, Asvab Verb, and RottInd.

${ }^{a}$ Significant at $1 \%$.

${ }^{\mathrm{b}}$ Significant at $5 \%$.

${ }^{\mathrm{c}}$ Significant at $10 \%$.

${ }^{\mathrm{d}}$ Significant at $15 \%$.

'Sum of log likelihoods from two separate probit estimates, one of school completion, the other from alcohol onset.

${ }^{f}$ Marginal probability averaged over the entire sample.

${ }^{g} \mathrm{SE}$ based on sample average marginal probability.

${ }^{\text {h}}$ Estimation restriction sets $\rho=0$; identical to estimating separate probits.

Source: NLSY 1979-96.

The primary difference between this analysis and the one reported in the previous subsection is that the difference between the probit marginal effect of alcohol consumption onset and the bivariate probit marginal effect is now much smaller, despite the positive and significant correlation between the unobserved determinants of alcohol consumption onset and schooling completion. The estimated probit marginal effect is a $9.5 \%$ reduction in the probability of completing school, whereas the means of the estimated bivariate probit marginal effects varies from an $11.2 \%$ reduction to a $13.7 \%$ reduction in the probability of schooling completion. ${ }^{28}$ According to our analysis, if it were not for social factors acting positively on the young men and women, there would be more schooling problems than are observed.

Although other results are not reported here, it is worth noting that many of the same variables affect schooling completion and alcohol onset the same way as mentioned in the preceding section. Generally, the size of the parameter estimates is much lower here than in the preceding set of estimates. An important difference (not included in the table) is in the statistical implication that the size of the family, parental education, and 
availability of reading material do not greatly improve the likelihood that a youth receives a high school diploma by the age of 20 over the receipt of a GED or a diploma later in life. In other words, family characteristics play an important role in pushing the youth to conclude their education in some way or another, but not necessarily the type of degree completed.

\section{Early Alcohol Consumption Onset and GED or Later-Life Diploma Attainment Compared to Nongraduates}

Our last set of results is presented in Table 6. This table displays estimates of high school success for those who initially quit school, some of whom later returned. Therefore, high school success is described as receiving a GED (or, in rare instances, returning for a high school diploma) after the age of 20 . The effect of alcohol consumption onset on educational success remains the focus. Hence, for the sample of nondiploma (by age 20) earning individuals, ${ }^{29}$

$$
E_{i}=\left\{\begin{array}{cc}
1 \text { (receives a } & \\
\text { G.E.D.), } & \text { if } E_{i}^{*}>0 \\
0 \text { (does not reveive } & \\
\text { G.E.D.), } & \text { otherwise. }
\end{array}\right.
$$

Because the results in this subsection are concerned with a smaller sample of individuals, those who do not receive a diploma by the age of 20, the results suggest whether there are any differences in early life circumstances between those dropouts who eventually return and those who do not. Importantly, because return may occur at much later ages (i.e., late enough for many early life circumstances to be forgotten) for most of the sample, it is surprising that the results do pinpoint the importance of alcohol consumption onset still. However, an additional problem is noticed in the tables: Generally, the excluded variables are not strong and significant predictors of alcohol consumption onset. For that reason, we do not place unshakable faith in the estimated marginal effects from the biprobit analysis. In the first column, where the probit estimates are presented, the estimated effect of youth alcohol consumption onset is negligible, whereas in all of the bivariate cases, the mean estimated marginal effect approaches a 50\% reduction in the probability of returning to school. Furthermore, the estimated correlation between unobserved factors affecting schooling and alcohol onset decisions approaches unity. In other words, there are too many unobserved factors in each of the two estimated equations; the result is the identification problems alluded to in the notes.

The difficulty we had in estimating this set of equations is, however, not all that surprising. As we found initially, alcohol consumption onset and family background characteristics play an important role in an individual's schooling decisions. However, although schooling is an investment decision, we would expect that youth variables will have been mostly forgotten when individuals decide whether to return to school. Alcohol consumption preceding high school is contemporaneous and relevant, primarily because we examined high school decisions. Further analysis into education and alcohol 
openUP

consumption, especially consideration of when and if people choose to return to school will require more contemporaneous alcohol consumption variables.

\section{TABLE 6}

Estimates of Early Alcohol Consumption (by Age 14) on GED or Later-Life Diplomas Compared to Noncompletion

\begin{tabular}{|c|c|c|c|c|c|c|}
\hline \multirow[b]{2}{*}{ Sample $N=2,893$} & \multirow{2}{*}{$\begin{array}{c}\text { Probit } \\
\text { Estimate }\end{array}$} & \multicolumn{5}{|c|}{$\begin{array}{l}\text { Bivariate Probit Specification Exclusion } \\
\text { Restriction for Onset by } 14\end{array}$} \\
\hline & & MLDA14 & LNtax14 & One Rel. & Two Rels. & All Four \\
\hline $\begin{array}{l}\text { Effect on education by } \\
\text { Onset at age } 14\end{array}$ & $\begin{array}{c}-0.0045 \\
(0.1072)\end{array}$ & $\begin{array}{r}-1.5789^{\mathrm{a}} \\
(0.1317)\end{array}$ & $\begin{array}{r}-1.5900^{\mathrm{a}} \\
(0.1255)\end{array}$ & $\begin{array}{r}-1.4887^{\mathrm{a}} \\
(0.2218)\end{array}$ & $\begin{array}{r}-1.4985^{\mathrm{a}} \\
(0.2221)\end{array}$ & $\begin{array}{r}-1.5279^{\mathrm{a}} \\
(0.1840)\end{array}$ \\
\hline Marginal effect & $\begin{array}{c}-0.0018 \\
(0.0428)\end{array}$ & $\begin{array}{l}-0.4824^{\mathrm{f}} \\
(0.1461)^{\mathrm{g}}\end{array}$ & $\begin{array}{l}-0.4840^{f} \\
(0.1476)^{g}\end{array}$ & $\begin{array}{r}-0.4664^{\mathrm{f}} \\
(0.1346)^{\mathrm{g}}\end{array}$ & $\begin{array}{l}-0.4683^{\mathrm{f}} \\
(0.1360)^{\mathrm{g}}\end{array}$ & $\begin{array}{r}-0.4741^{f} \\
(0.1403)^{g}\end{array}$ \\
\hline Male & $\begin{array}{c}0.2417 \\
(0.3134)\end{array}$ & $\begin{array}{l}0.4721^{\mathrm{b}} \\
(0.2332)\end{array}$ & $\begin{array}{c}0.4791^{\mathrm{b}} \\
(0.2326)\end{array}$ & $\begin{array}{r}0.4261^{\mathrm{c}} \\
(0.2479)\end{array}$ & $\begin{array}{r}0.4313^{\mathrm{c}} \\
(0.2479)\end{array}$ & $\begin{array}{r}0.4459^{\mathrm{c}} \\
(0.2479)\end{array}$ \\
\hline Male $\times$ Education Effect of Onset & $\begin{array}{r}-0.06858 \\
(0.1308)\end{array}$ & $\begin{array}{c}0.1367 \\
(0.0978)\end{array}$ & $\begin{array}{r}0.1384^{\mathrm{d}} \\
(0.0965)\end{array}$ & $\begin{array}{l}0.12 \\
(0.1074)\end{array}$ & $\begin{array}{c}0.1225 \\
(0.1075)\end{array}$ & $\begin{array}{c}0.1265 \\
(0.1032)\end{array}$ \\
\hline Effect of MLDA14 on Onset by 14 & $\begin{array}{l}-0.0071 \\
(0.0226)\end{array}$ & $\begin{array}{l}0.019 \\
(0.0173)\end{array}$ & & & & $\begin{array}{c}0.012 \\
(0.0187)\end{array}$ \\
\hline Effect of LNtax14 on Onset by 14 & $\begin{array}{r}-0.0052 \\
(0.0345)\end{array}$ & & $\begin{array}{c}-0.0344 \\
(0.0267)\end{array}$ & & & $\begin{array}{r}-0.0295 \\
(0.0293)\end{array}$ \\
\hline Effect of one relative on Onset by 14 & $\begin{array}{r}0.1204^{\mathrm{c}} \\
(0.0689)\end{array}$ & & & $\begin{array}{r}0.1335^{\mathrm{b}} \\
(0.0571)\end{array}$ & & $\begin{array}{r}0.0907^{\mathrm{d}} \\
(0.0610)\end{array}$ \\
\hline $\begin{array}{l}\text { Effect of two relatives on } \\
\text { Onset by } 14\end{array}$ & $\begin{array}{r}0.1285^{\mathrm{c}} \\
(0.0745)\end{array}$ & & & & $\begin{array}{l}0.1368^{\mathrm{b}} \\
(0.0606)\end{array}$ & $\begin{array}{c}0.0785 \\
(0.0642)\end{array}$ \\
\hline Male & $\begin{array}{l}1.363^{\mathrm{a}} \\
(0.2292)\end{array}$ & $\begin{array}{r}0.8605^{\mathrm{b}} \\
(0.4121)\end{array}$ & $\begin{array}{c}0.8597^{\mathrm{b}} \\
(0.4124)\end{array}$ & $\begin{array}{c}0.8251^{\mathrm{b}} \\
(0.4196)\end{array}$ & $\begin{array}{c}0.8332^{\mathrm{b}} \\
(0.4182)\end{array}$ & $\begin{array}{r}0.8012^{\mathrm{c}} \\
(0.4158)\end{array}$ \\
\hline$\rho$ & $0^{\mathrm{h}}$ & $0.8714^{\mathrm{a}}$ & $0.8782^{\mathrm{a}}$ & $0.8162^{\mathrm{a}}$ & $0.8222^{\mathrm{a}}$ & $0.8417^{\mathrm{a}}$ \\
\hline$\chi_{1}^{2}$ & & 24.623 & 26.017 & 9.783 & 9.535 & 12.958 \\
\hline Log likelihood & $-3,186.42^{\mathrm{e}}$ & $-3,176.78$ & $-3,176.54$ & $-3,173.81$ & $-3,174.26$ & $-3,172.04$ \\
\hline
\end{tabular}

Notes: SEs are in parentheses. Other variables used in regression and not reported in the table: Nonwhite, \%FamInt, \%FamIntMiss, Siblings, NotOldest, OlderSibHS, MomEd, MomEdMiss, DadEd, DadEdMiss, Reading Available, Raised Catholic, Religious, Urban, \%HSDip, Asvab Verb, and RottInd.

${ }^{a}$ Significant at $1 \%$

${ }^{\mathrm{b}}$ Significant at $5 \%$.

'Significant at $10 \%$,

${ }^{\mathrm{d}}$ Significant at $15 \%$.

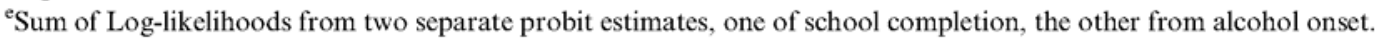
${ }^{\mathrm{f}}$ Marginal probability averaged over the entire sample.

${ }^{\mathrm{g}} \mathrm{SD}$ based on sample average marginal probability.

${ }^{\mathrm{h}}$ Estimation restriction sets $\rho=0$; identical to estimating separate probits.

Source: NLSY 1979-96.

\section{CONCLUSION}

In this article, we have reported results from the examination of the determinants of alcohol consumption onset by the age of 14 and different measures of high school completion, where we controlled for the endogeneity of schooling and alcohol decisions with alcohol policy variables as well as family controls. The general conclusion to be drawn from the analysis is that alcohol consumption onset greatly reduces the probability of high school success, especially if high school success is meant to include the receipt of a high school diploma by the age of 20 . The primary concern when estimating the effect of alcohol consumption on education is the ability to control for the simultaneity of the two decisions. Research by Cook and Moore (1993), Yamada et al. (1996), and Moore and Cook (1995) have found significant negative effects of alcohol and drug use on 
education, whereas Dee and Evans (1999) and Koch and Ribar (2001) have found negative but insignificant or negative and significant (but small) effects of alcohol use on education. In contrast to the preceding publications, we have found negative significant and large effects of alcohol consumption onset on education. Our results are due to the fact that we look at alcohol consumption decisions that predate the education decisions and the fact that we employ an empirical technique that allows for the estimation of the unobserved correlation between the two endogenously determined variables. Most previous studies have not been able to examine the importance of the social nature of schooling and drinking. Our research suggests that further research into peer interactions and their effects on human capital decisions will be important.

Like many previous researchers, we find that alcohol tax policies affect alcohol use, and, therefore, tax policies can influence education success for high school youths. On the other hand, like Dee and Evans (1999), we do not find that alcohol control policies, measured by the legal minimum purchase age law, affect alcohol consumption onset. This finding results despite the fact that we included a family control for older siblings, who we find to be contributing to the alcohol consumption of their younger siblings.

In addition, we also find that individuals from families with a history of alcohol problems are more likely to consume alcohol on a regular basis at an early age. Although we did not have data, the implication of the research is that alcohol treatment programs may have a greater benefit than alcohol control or tax policies. The importance of social factors in counterbalancing the negative effects of alcohol consumption (although those same factors may also contribute to alcohol consumption in practice) need to be further recognized. Appropriate school-level programs that encourage participation in social activities could increase the schooling success of many youths, especially because these social activities will not promote alcohol consumption.

The results reported here suggest an interesting research agenda, one that focuses much more carefully on duration analysis and the hazards associated with difficulties resulting from adolescent drinking. Our results suggest that alcohol consumption initiation at an early age will increase the hazard of dropout, and, therefore, it may increase the duration of school absence. ${ }^{30}$ Our results further highlight the importance of modeling events that are proximate in time; hazard analysis could do this. Finally, due to the nature of social interactions, it might be possible to examine changes in peer structures and its effect on both alcohol consumption and schooling decisions. Until more is understood concerning absence from school, return to school, peer interactions, and job market behavior for youthful consumers of alcohol, there remain many interesting questions to be examined in this area of the literature.

\section{Footnotes}

*We thank two anonymous referees, Paul E. Jensen, seminar participants at the University of Pretoria and Drexel University, as well as participants at the International Atlantic Economic Association Meetings in Charleston and Athens, participants at the 
Western Economic Association Meetings, and participants in the African Econometric Society Modelling Conference in Kruger Park, South Africa for their helpful comments.

1. Dropping out of school may allow more time for income-earning activities, and thus increase the potential alcohol consumption set.

2. Importantly, even under extreme assumptions concerning rationality, it is unlikely that high school continuation decisions (during high school, for example) will influence the decision to drink preceding high school.

3. A 95\% confidence interval around their estimates suggests that alcohol consumption could reduce postsecondary education anywhere from not at all to up to four years.

4. Although we do not directly address these questions, because we do not have exact onset of alcoholism symptoms in the NLSY, the raw correlation between alcohol onset before the age of 14 (which means consumption onset by 1979) and alcoholism (which is measured with the 1988 wave of the NLSY) is 0.09 and is significant at the $0.01 \%$ level.

5Burgess and Propper (1998), in related work, find an increase in earnings related to early alcohol experiences, that is, those beginning before the age of 18 , suggesting that early alcohol experiences are not likely to have lingering negative effects.

6. The model, more commonly referred to as a bivariate probit, has been used to examine a number of different issues in economics. Our model is derived in part from the discussion in Ribar (1994).

7. Although it is rarely acceptable to use less information than more (as we do here with the dichotomous measure of alcohol onset rather than a continuous measure, which could be incorporated into the analysis), using the dichotomous measure of alcohol consumption removes one possible direction of causality. It is not plausible that an individual's later schooling decisions will determine current drinking behavior. However, using the continuous analog of drinking would make it difficult to determine whether drinking was caused by poor schooling performance or vice versa.

8. We apply the standard normalization, $\sigma_{\Sigma}=\sigma_{\vee}=1$, for ease of interpretation.

9. We also apply multiple restrictions and test for overidentification.

10. The NLSY contains weights, not used here, which make the estimates more nationally representative. The survey oversampled blacks, Hispanics, and underprivileged whites.

11. The total sample of females was reduced to 4,749 and the total sample of males was reduced to 4,401 after observations without complete information were removed. 
12. Each year, the NLSY asked respondents whether they had completed high school within the past year. If they had completed high school, they were further asked whether they had received a diploma or a GED.

13. There were some disagreements between the 1982 and 1983 responses. In the case of disagreement, we chose the younger response in each of those years. As an extreme correction, we also dropped all responses with a disagreement; the estimates were not significantly different, so we stayed with the younger response.

14. One concern from using retrospective data is that recall may be better for individuals closer to the age they are recalling. Results of cohort analyses show unimodal distributions centered at age 18 and mass points at 0 ; the mass point at 0 measures the extent of nondrinkers in the cohort. As expected, older cohorts had smaller mass points at 0 , as older individuals have had more opportunity to begin consuming alcohol. Similarly, younger cohorts were more likely to report more youthful alcohol consumption onset. However, it is not apparent that the cohort effects are inherently due to recall error or differences in the age distributions; either interpretation could be valid.

15. After very careful analysis, it was determined that although males and females differed in their drinking and schooling success, they did not significantly differ in their responses to the exclusion restrictions used for identification of the model. A dummy variable to control for gender was incorporated in the analysis to extract the differences in behavior between men and women. We thank a reviewer for bringing this feature to our attention.

16. There were 588 young females who did not receive any high school degree, there were 585 young females who received either a GED or a diploma at an age later than 20; that makes 1,173 out of 4,321 (or 27.1\%) young females who did not consume alcohol by the age of 14 and did not receive a diploma by the age of 20. Similarly, there were 168 out of $428(39.3 \%)$ young females who did initiate alcohol consumption by the age of 14 and did not receive their diplomas by the age of 20 .

17. For the male sample, there were 593 nondegree recipient nondrinkers and 569 GED and later-life diploma recipient nondrinkers. In other words, 1,162 out of the 3,587 young males who did not consume alcohol regularly by age 14 also did not receive a diploma by the age of 20. On the other hand, 390 out of the 814 young men who did consume alcohol regularly by the age of 14 also did not complete their high school diplomas by the age of 20 .

18. Kruskal-Wallis tests of similarities across samples reject that men and women drink by the same age $\left(\chi_{1}^{2}=61.62\right)$ and graduate at the same rates $\left(\chi_{1}^{2}=33.83\right)$.

19. For this test, the calculated test statistic for females is $\chi_{1}^{2}=6.96$. For males, the calculated test statistic is $\chi_{1}^{2}=32.49$. 
20. The data also contains scores on the 10 ASVAB sections. Verbal scores were chosen due to the statistical fact that they were highly correlated with all other ASVAB section scores; the lowest correlation coefficient was 0.60 , and the highest was 0.98 . Analyses were run with other ASVAB section scores as the control for ability, but no obvious differences were noticed.

21. A large number of different specifications were examined to determine the validity of a pooled analysis over an analysis separated by gender. Log-likelihood ratio tests generally confirmed the results posted in Table 1: Young men and women have different drinking and schooling behaviors. However, log-likelihood tests also showed that men and women did not respond differently to the identification exclusion restrictions. For that reason, only the pooled results are reported in the paper. The separated sample results are available on request.

22. The remaining results are available on request.

23. We also estimated the relationship dropping all GED recipients. The results were qualitatively the same, although quantitatively stronger, so we report only the full sample results.

24. Recall that we are not saying that drinking at an early age leads to an increased probability of completing school; rather, we are saying that the negative impact of drinking at an early age is understated, due to the complementary social nature of schooling and drinking. As an extreme example, if it were not for the ability to socialize with contemporaries, it may be the case that more students would dropout of school than currently do.

25. One referee suggested that the effect of the minimum legal drinking age might be nonlinear. We investigated that possibility by allowing for dummy variables at different age categories. The effect of the different definitions was insignificant in all cases, and, for that reason, we do not report those results here.

26. It is possible that the only reason these people know they have relatives with a drinking problem is that they have been told by other family members that they may turn out to be just like so-and-so. In that sense, the knowledge is gained later and cannot be considered as a determinant to their actual decision.

27. We did also analyze other subsamples; for example, we compared diploma recipients by age 20 with those who had not completed their diploma by the age of 20 . The results presented here only pertain to the first analysis, because the subsampling did not greatly affect the conclusions.

28. The mean for the beer tax exclusion is only a $7.5 \%$ reduction; however, the need for the bivariate probit in that case is rejected. 
openUP

29. Other subsamples were considered. For example, we looked only at individuals who had earned a GED compared to those who did not complete anything. In all of these cases, identification was an issue due to relatively small sample sizes, and, more important, due to minimal variations in the explanatory variables; for that reason, we focus on the sample of nondiploma earners, under which scenario we were able to obtain estimates, although those estimates are not ideal.

30. In related work, Koch and McGeary (2003) are investigating dropout hazards. Preliminary results suggest that this hazard increases with the number of years an individual has been drinking preceding the year of school in question. However, their analysis has not yet included absence duration.

\section{REFERENCES}

- Becker, G. S. "A Theory of the Allocation of Time." Economic Journal, 75, 1965, 493-517.

- Becker, G. S. A Treatise on the Family, Cambridge, MA : Harvard University Press, 1991.

- Benham, L., and A. Benham. "Employment, Earnings and Psychiatric Diagnosis," in Economic Aspects of Health, edited by V. Fuchs. Chicago: University of Chicago Press, 1982, 203-20.

- Burgess, S. M., and C. Propper. "Early Health Related Behaviours and Their Impact on Later Life Chances: Evidence from the U.S." Health Economics, 7, 1998, 381-99.

- Center for Human Resource Research, 1998, http://0-www.chrr.ohiostate.edu.innopac.up.ac.za:80/surveys.html (accessed July 1999).

- Cook, P., and M. J. Moore. "Drinking and Schooling." Journal of Health Economics, 12(4), 1993, 411-29.

- Deas, D., P. Riggs, J. Langenbucher, M. Goldman, and S. Brown. "Adolescents Are Not Adults: Development Considerations in Alcohol Users." Alcoholism: Clinical and Experimental Research, 24(2), 2000, 232-37.

- Dee, T. S., and W. N. Evans. "State Alcohol Policies, Teen Drinking and Traffic Fatalities," Journal of Public Economics, 72(2), 1999, 289-315.

- Figlio, D. N. "The Effect of Drinking Age Laws and Alcohol-Related Crashes: Time-Series Evidence from Wisconsin." Journal of Policy Analysis and Management, 14(4), 1995, 555-66.

- Grant, B. F., and D. A. Dawson. "Age at Onset of Alcohol Use and Its Association with DSM-IV Alcohol Abuse and Dependence: Results from the National Longitudinal Alcohol Epidemiological Survey." Journal of Substance Abuse, 9, 1997, 103-10.

- Grossman, M. "On the Concept of Health Capital and the Demand for Health." Journal of Political Economy, 80(2), 1972, 223-55.

- Harwood, H. J., A. Cruze, P. Kristiansen, J. Collins, and D. Jones. "Economic Costs to Society of Alcohol and Drug Abuse and Mental Illness: 1980." Technical Report, Research Triangle Institute, 1984. 
- Koch, S. F., and K. A. McGeary. "The Hazard of Alcohol and Other Drug Consumption on School Leaving and Return." Working Paper, University of Pretoria, 2003.

- Koch, S. F., and D. C. Ribar. "A Siblings Analysis of the Effects of Alcohol Consumption Onset on Educational Attainment." Contemporary Economic Policy, 19(2), 2001, 162-74.

- Moore, M. J., and P. J. Cook. "Habit and Heterogeneity in the Youthful Demand for Alcohol." NBER Working Paper No. 5152, 1995.

- Mullahy, J., and J. L. Sindelar. "Alcoholism, Work and Income." Journal of Labor Economics, 11(3), 1993, 494-520.

- Mullahy, J., and J. L. Sindelar. "Alcoholism and Income: The Role of Indirect Effects." Milbank Quarterly, 72(2), 1994, 359-75.

- Ribar, D. C. "Teenage Fertility and High School Completion." Review of Economics and Statistics, 76(3), 1994, 413-24.

- Rice, D. P. "The Economic Cost of Alcohol Abuse and Alcohol Dependence: 1990." Alcohol Health and Research World, 17(1), 1993, 10-12.

- Rice, D. P., S. Kelman, L. S. Miller, and S. Dunmeyer. "The Economic Cost of Alcohol and Drug Abuse and Mental Illness: 1985." Technical Report, Office of Financing and Coverage Policy. Alcohol, Drug Abuse, and Mental Health Administration, U.S. Department of Health and Human Services, University of California-San Francisco,

- San Francisco, CA

- Weschler, H., J. E. Lee, M. Kuo, and H. Lee. "College Binge Drinking in the Late 1990s: A Continuing Problem." Technical Report, College Studies Report, 2000.

- Wilson, N., V. Battistich, S. L. Syme, and W. T. Boyce. "Does Elementary School Alcohol, Tobacco, and Marijuana Use Increase Middle School Risk?" Journal of Adolescent Health, 30, 2002, 442-47.

- Wolaver, A. M. "Effects of Heavy Drinking in College on Study Effort, Grade Point Average, and Major Choice." Contemporary Economic Policy, 20(4), 2002, 415-28.

- Yamada, T., M. Kendix, and T. Yamada. "The Impact of Alcohol Consumption and Marijuana Use on High School Graduation." Health Economics, 5(1), 1996, 77-92. 